\title{
Cost effective measures to standardize serum 25(OH)D values from completed studies
}

\author{
C. T. Sempos ${ }^{1,2}$ - R. A. Durazo-Arvizu ${ }^{3}$ G. D. Carter $^{4}$
}

Received: 1 February 2017 / Accepted: 17 February 2017 / Published online: 20 March 2017

(C) International Osteoporosis Foundation and National Osteoporosis Foundation 2017

$\begin{array}{ll}\text { Abbreviations } \\ \text { 25OHD } & \text { Serum Total 25-hydroxyvitamn D } \\ \text { CAP } & \text { College of American Pathologists } \\ \text { CDC } & \text { Centers for Disease Control and Prevention } \\ \text { DEQAS } & \text { Vitamin D External Quality Assessment Scheme } \\ \text { NHANES } & \text { National Health and Nutrition Examination } \\ & \text { Survey } \\ \text { NIST } & \text { National Institute of Standards and Technology } \\ \text { RMP } & \text { reference measurement procedure } \\ \text { VDSP } & \text { Vitamin D Standardization Program }\end{array}$

25-Hydroxyvitamin $\mathrm{D}[25(\mathrm{OH}) \mathrm{D}]$ assay variation is thwarting attempts to develop evidenced-based criteria for defining clinical states of vitamin D status, i.e., deficiency, insufficiency, sufficiency, and toxicity. Since 1968 when $25(\mathrm{OH}) \mathrm{D}$ was discovered through 2016, some 60,000 papers have been published with only a handful based on standardized $25(\mathrm{OH}) \mathrm{D}$ measurements [1]. This lack of standardized 25(OH)D measurements makes it difficult if not impossible to conduct meta analyses of the relationship of $25(\mathrm{OH}) \mathrm{D}$ to vitamin D clinical states in order to develop 25(OH)D cut-points.

The challenge for the vitamin $\mathrm{D}$ field is to select key studies among those completed studies and, where stored samples

C. T. Sempos

semposch@mail.nih.gov

1 Office of Dietary Supplements, National Institutes of Health, 6100 Executive Blvd., Rm. 3B01, Bethesda, MD 20892-7517, USA

2 FedEx, Rockville, MD 20852, USA

3 Department of Public Health Sciences, Loyola University Stritch School of Medicine, Maywood, IL 60153, USA

4 DEQAS Organiser, Charing Cross Hospital, London W6 8RF, UK exist, standardize the $25(\mathrm{OH}) \mathrm{D}$ measurements by calibrating the old values to values which are traceable to the Reference Measurement Procedures (RMPs) of the National Institute for Standards and Technology (NIST), Ghent University, and the Centers for Disease Control and Prevention (CDC). This is referred to as Retrospective Standardization. To accomplish retrospective standardization, the Vitamin D Standardization Program (VDSP) has developed two options for conducting calibration studies [2]. Option 1 has three steps: [1] Use results from the measurement of 40-50 single donor serum samples with RMP target values to develop an equation to convert values based on the current assay to the NIST-Ghent-CDC RMPs, [2] re-measure a statistically defined subsample of the stored sera from the completed study and develop an equation to convert past values to the current assay, and [3] merge the two sets of equations to form a single "Master Equation" that is used to convert past study $25(\mathrm{OH}) \mathrm{D}$ values to the NISTGhent University-CDC RMPs. A fourth step in this option might be to send a duplicate set of samples to a certified traceable laboratory for confirmation.

Option 2 is similar except for the fact that all new $2(\mathrm{OH}) \mathrm{D}$ measurements are made by a laboratory which is certified to be traceable to the RMPs [2]. The traceable laboratory measures a statistically representative sample of all the stored sera and then, using regression analysis, a Master Equation is developed to predict NIST-Ghent-CDC traceable laboratory values from the original assay values. The Master Equation is then used to convert all of the old data to NIST-Ghent-CDC traceable values.

Developing an affordable modified Option 1 is the goal of Drs. Jakab et al. in a thoughtful paper published recently in Osteoporosis International [3]. The authors propose using values from the analysis of samples distributed as part of the Vitamin D External Quality Assessment Scheme (DEQAS) to standardize the $20625 \mathrm{OHD}$ measurements from the HunMen study by calibrating them to the RMPs. 
The problem with Option 1 is its cost. A set of 40 single donor serum samples with RMP target values can cost up to $\$ 3000$ 4000. That along with the costs associated with the normal use of an assay can make the calibration of the old $25(\mathrm{OH}) \mathrm{D}$ values prohibitively expensive. DEQAS is an accuracy-based EQAS which distributes five samples per quarter. All the samples distributed have target values assigned to them by one of the RMPs currently by NIST. In addition, all the distributed samples originate from donations that are collected and prepared by Solomon Park, Seattle, Washington, USA using exacting procedures to guarantee their commutability [4]. Finally, DEQAS's yearly subscription (for 20 samples) is $£ 200-250$ per year depending on participation location. This makes it affordable to laboratories around the world.

The authors followed Option 1 perfectly. They, with their DiaSorin Liaison assay, participate in DEQAS. The master equation was developed from the DEQAS results for the five samples submitted shortly after re-measuring all 206 samples with their assay. Moreover, rather than re-measuring a statistically defined subsample, of all the samples, Jakab et al. re-measured all the samples from the data set. We have found that the minimal number of samples to be re-measured is approximately 100-150 [5, 6]. In light of those results, re-measuring all the samples was a reasonable decision.

So, why the editorial? The reason for this editorial is to update Option 1 based on our experience which suggests that five samples may not be enough. If the results from the plot used to develop the Master Equation are linear, as they appear to be from the HunMen study, then five samples may be sufficient. The problem is that the Master Equation may not be linear. We have found using Option 2 that it is often the case that the performance characteristics of the laboratory's assay change at some point over the concentration range. In that case, the Master Equation can be characterized being a piecewise regression model where the two lines intersect at the point where the performance characteristics change [5-7]. The departures from linearity vary from the very subtle to the quite dramatic. The point of intersection in published research has varied from 49 to $121 \mathrm{nmol} / \mathrm{L}$ or indeed at any point over much of the 25OHD distribution.

An essential question is whether departures from linearity can be detected with only 5 DEQAS samples as the basis for developing a Master Equation in Option 1 ? Our fear is that many times the departures from linearity will be missed when the Master Equation has a foundation of only five samples. Then how many samples should be used? Ideally at least 100 samples, but we know that to be impractical so as a compromise we suggest that no fewer than 40 samples (2 years of
DEQAS distributions) be used in developing the Master Equation [8]. These 40 samples are in addition to the re-measurement of a statistically defined subsample or, as Jakab et al. did, re-measurement of all the stored study samples. DEQAS participants can use samples from previous distributions and/or purchase additional samples from the DEQAS archive. These are also available to non-participants in DEQAS. This is just another excellent reason for all research and clinical laboratories to participate in DEQAS or the other accuracy-based performance testing (PT) program conducted by the College of American Pathologists (CAP), i.e., Accuracy-based Vitamin D (ABVD) Survey.

In conclusion, the paper by Drs. Jakab et al. is a major advance in promoting the standardization of completed studies. Suggesting the use of DEQAS samples to develop the Master Equation for VDSP Option 1 was a master stroke.

\section{Compliance with ethical standards}

Disclaimer The findings and conclusions in this report are those of the authors and do not necessarily represent the views of the National Institutes of Health or the US Department of Health and Human Services.

\section{Conflict of interest None.}

\section{References}

1. Binkley N, Dawson-Hughes B, Durazo-Arvizu R, Thamm M, Tian L, Merkel JM, Jones JC, Carter GD, Sempos CT (2016) Vitamin D measurement standardization: the way out of the chaos. J Steroid Biochem Mol Biol. doi:10.1016/j.jsbmb.2016.12.002

2. Sempos CT, Vesper HW, Phinney KW, Thienpont LM, Coates PM et al (2012) Vitamin D status as an international issue: national surveys and the problem of standardization. Scand J Clin Lab Investig 72(Suppl 243):32-40

3. Jakab E, Kalina E, Petho Z, Pap Z, Balogh A, Grant WB, Bhattoa HP (2017) Standardizing 25-hydroxyvitamin D data from the HunMen cohort. Osteoporos Int. doi:10.1007/s00198-017-3924-4

4. NCCLS (1999) Preparation and validation of commutable frozen human serum pools as secondary reference materials for cholesterol measurement procedures; approved guidelines. NCCLS document C37-A (ISBN 1-56238-392-2). NCCLS, 940 West Valley Road, Suite 1400, Wayne, Pennsylvania 19087-1898 USA

5. Cashman KD, Holvik K, Andersen R, Linneberg A, LambergAllardt C, Tetens I, Gronberg IM, Meyer HE, Keily M, Dowling K, Skrabakova Z, Lundqvist A, Koponen P, Sundvall J, Koskinen S, Nystrup LL, Thuesen BH, Sempos CT, Durazo-Arvizu RA, Skrakova Z (2015) Standardizing serum 25-hydroxyvitamin D data from four Nordic population samples using the vitamin D standardization program protocols: shedding new light on vitamin $\mathrm{D}$ status in Nordic individuals. Scand J Clin Lab Inves 75(7):549-561

6. Cashman KD, Dowling KG, Škrabáková Z, Gonzalez-Gross M, Valtueña J, De Henauw S, Moreno L, Damsgaard CT, Michaelsen KF, Mølgaard C, Jorde R, Grimnes G, Moschonis G, Mavrogianni C, 
Manios Y, Thamm M, Mensink GB, Rabenberg M, Busch MA, Cox L, Meadows S, Goldberg G, Prentice A, Dekker JM, Nijpels G, Pilz S, Swart KM, van Schoor NM, Lips P, Eiriksdottir G, Gudnason V, Cotch MF, Koskinen S, Lamberg-Allardt C, Durazo-Arvizu RA, Sempos CT, Kiely M (2016) Vitamin D deficiency in Europe: pandemic? Am J Clin Nutr 103(4):1033-1044. doi:10.3945/ajcn.115. 120873

7. Schleicher RL, Sternberg MR, Lacher DA, Sempos CT, Looker AC, Durazo-Arvizu RA, Yetley EA, Chaudhary-Webb M, Maw KL,
Pfeiffer CM, Johnson CL (2016) A Method-bridging Study for Serum 25-hydroxyvitamin D to Standardize Historical Radioimmunoassay Data to Liquid Chromatography-Tandem Mass Spectrometry. National Health Statistics Reports, Number 93

8. NCCLS (2002) Method comparison and bias estimation using patient samples; Approved guideline - Second Edition. NCCLS document EP9-A2 (ISBN 1-56238-392 - 2). NCCLS, Clinical and Laboratory Standards Institute. 950 West Valley Road, Suite 2500 Wayne, PA 19087 USA 